\title{
Biological Control of Pierce's Disease in the Vineyard with Strains of Xylella fastidiosa Benign to Grapevine
}

\author{
D. L. Hopkins, University of Florida, Mid-Florida Research and Education Center, Apopka 32703
}

\begin{abstract}
Hopkins, D. L. 2005. Biological control of Pierce's disease in the vineyard with strains of $X y$ lella fastidiosa benign to grapevine. Plant Dis. 89:1348-1352.

Naturally occurring strains of Xylella fastidiosa Wells et al. that were weakly virulent or avirulent to grapevine were inoculated into the lower internodes of Vitis vinifera L. cv. Carignane plants in the greenhouse and challenge inoculated with pathogenic strains 2 weeks later. Several strains provided some reduction in symptom development. Most effective in preventing or slowing the development of Pierce's disease in the greenhouse tests were a strain from sycamore and two from elderberry. In a 2-year test on 'Himrod' grape in the vineyard, strain Syc86-1 (from sycamore), but not strain PD-1 (from grapevine), was effective in limiting the development of Pierce's disease. In tests on new vineyard plantings of 'Flame Seedless' and 'Cabernet Sauvignon', six strains of $X$. fastidiosa were evaluated for biological control of the natural progression of Pierce's disease. Only strain EB92-1 (from elderberry) provided good control of the disease in both Flame Seedless and Cabernet Sauvignon. Strain Syc86-1 was ineffective in these vineyard tests. Grape strain PD95-6 did lower disease severity in Flame Seedless when compared with nontreated vines, and grape strain PD91-2 delayed symptoms in Cabernet Sauvignon for 12 to 18 months. Biological control by inoculation of susceptible grapevines with benign strains of $X$. fastidiosa, especially strain EB92-1, appears to have the potential to control Pierce's disease in commercial vineyards in Florida and other areas where the disease occurs.
\end{abstract}

Pierce's disease (PD) of grapevine first was reported in California in 1892 and was known as the California vine disease. Gram-negative, xylem-limited bacteria were discovered in association with PD of grapevine in 1973 and were called rickettsia-like bacteria $(9,16)$. The bacterium first was grown in axenic culture in 1978 (4). In a taxonomic study, the name Xylella fastidiosa (Wells et al.) was proposed to establish a new genus with one species to include all of the known strains of fastidious, gram-negative, xylemlimited bacteria (26). In 2004, three subspecies of $X$. fastidiosa were described, subsp. piercei, multiplex, and pauca (23). $X$. fastidiosa causes economic losses in many agriculturally important plants, including grapevine, peach, plum, coffee, and citrus $(7,13)$. It also causes leaf scorch and declines in many urban shade trees and shrubs, such as elm, oak, oleander, maple, and sycamore (10). The most important vectors of $X$. fastidiosa are members of the leafhopper subfamily Cicadellinae (sharpshooters) and of the spittlebug

Corresponding author: D. L. Hopkins

E-mail: dlhopkins@mail.ifas.ufl.edu

Florida Agricultural Experiment Station Journal Series No. R-10908.

Accepted for publication 9 August 2005.

DOI: 10.1094/PD-89-1348

(C) 2005 The American Phytopathological Society family Cercopidae (21). Similar to the bacterium, these insect vectors have very wide host ranges, consisting of both woody and herbaceous plants.

PD is especially damaging in the southeastern United States, where it is endemic and is the primary factor limiting the development of a grape industry based on the high-quality European grapes (Vitis vinifera L.) (18). All efforts to grow $V$. vinifera grapevines in Florida have failed, beginning with the early Spanish settlement in the sixteenth century (25). PD also is a limiting factor in the production of European grapes in parts of Mexico, Central America, and the southwestern United States. Several important species of leafhopper vectors of PD occur in the southeastern United States. Two of the most important vectors in Florida are $\mathrm{On}$ cometopia nigricans (Walker) and Homalodisca coagulata (Say) (glassywinged sharpshooter) (1,2). They have wide host ranges, migrate to grapevine in the spring, and reproduce on grapevines. In the past, PD epidemics erupted sporadically to cause severe losses in California vineyards $(18,20)$. The recent introduction and development of the glassy-winged sharpshooter in California makes PD an increased threat to California's grape industry.

Symptoms in PD-infected grapevines include marginal necrosis or scorching of leaves, wilting and drying of fruit, uneven maturation of canes, decline of vigor, delayed bud break in the spring, and death of the vine. The PD bacterium has a very wide host range. Reciprocal transmission tests indicate that PD of grapevine, almond leaf scorch, and alfalfa dwarf are caused by the same strain of X. fastidiosa (6). In 1951, insect transmissions of the PD causal agent demonstrated that its host range included members of at least 28 families of monocotyledonous and dicotyledonous plants, many of which were symptomless hosts (8).

Hot-water treatment of propagation wood is an effective way of preventing the spread of the PD strain of $X$. fastidiosa into new areas, but the only feasible control for $\mathrm{PD}$ once it occurs in an area is resistance (18). Different levels of tolerance have been observed in $V$. vinifera cultivars (22). In the southeastern United States, V. vinifera cultivars cannot be grown because of $\mathrm{PD}$; therefore, the grape industry is based on resistant hybrid bunch grapes (Vitis spp.) and muscadine cultivars (V. rotundifolia Michx.) (17). Insecticide sprays have not provided effective control.

Virulence to grape of $X$. fastidiosa strains originally obtained from grapevines with PD varies from avirulent to highly virulent $(11,12)$. Weakly virulent strains multiply and move systemically but more slowly in the plant, producing only minor symptoms in the host. Strains of $X$. fastidiosa obtained from elderberry (Sambucus canadensis L.) with leaf scorch symptoms will colonize grapevine ( $V$. vinifera), sometimes producing mild symptoms (11). A sycamore leaf scorch strain from Florida also colonizes grapevine (15). Restriction endonuclease fingerprinting with NotI and SfiI showed that there is a high degree of similarity between the strains from elderberry and grapevine, but distinct clusters exist (19).

There are numerous examples of prior inoculation of a host with a nonpathogenic, or pathogenic, isolate of a fungus, bacteria, or virus inducing systemic acquired resistance to the same virulent pathogen or other pathogens (24). In previous research, weakly virulent strains of $X$. fastidiosa provided protection against $\mathrm{PD}$ in greenhouse tests (14). Our previous experience with PD in the Mid-Florida Research and Education Center (MREC) vineyard in Leesburg was that $V$. vinifera cultivars begin to develop symptoms within 6 months of planting and begin to die within a year. Vines rarely lasted more than 3 to 4 years. Therefore, the vineyard at Leesburg was considered the most severe test of 
biological control of PD with benign strains of $X$. fastidiosa. If PD control can be obtained in central Florida vineyards, it should be effective in almost any other grape-growing area. The objectives of this study were to (i) identify naturally occurring avirulent or weakly virulent strains of $X$. fastidiosa that provide effective biological control of PD of grapevine in greenhouse tests and (ii) evaluate them for the biological control of PD in the vineyard in Florida where the disease is endemic and chronic.

\section{MATERIALS AND METHODS}

Bacterial strains. Strains of $X$. fastidiosa evaluated for biological control of PD in the greenhouse, vineyard, or both included the following PD strains that became weakly virulent during serial transfer: PD-1, originally isolated from $V$. vinifera growing in Leesburg, Florida; PD91-2, isolated from $V$. rotundifolia (muscadine grape) in Leesburg; PD94-1, isolated from a Vitis sp. (wild grapevine) growing in a citrus grove near Sanford, FL; and PD95-6, isolated from a Vitis sp. (hybrid bunch grape) in Leesburg. Two strains with other primary hosts that also colonized grapevine without producing PD symptoms were tested. These were Syc861 , originally isolated from Platanus occidentalis L. (sycamore) near Gainesville; and EB92-1, isolated from $S$. canadensis (elderberry) growing in a grape vineyard in Leesburg. In greenhouse tests, challenge inoculations were with the highly virulent strain of X. fastidiosa, PD92-8, obtained from a hybrid bunch grape in Leesburg. $X$. fastidiosa can lose virulence during longterm, serial transfer; therefore, strains were used after no more than five serial transfers after removal from $-70^{\circ} \mathrm{C}$ storage. Natural infection was utilized in vineyard evaluations of biological control of PD.

Greenhouse biological control tests. To prepare inoculum suspensions of the weakly virulent biocontrol strains and the highly virulent pathogenic strains, cultures were grown to log phase (4 to 6 days) on PD3 medium (5). Bacteria were scraped off the plates and suspended in a succinatecitrate-phosphate buffer (SCP) composed of disodium succinate, $1.0 \mathrm{~g} / \mathrm{liter}$; trisodium citrate, $1.0 \mathrm{~g} / \mathrm{liter} ; \mathrm{K}_{2} \mathrm{HPO}_{4}, 1.5$ $\mathrm{g} / \mathrm{liter}$; and $\mathrm{KH}_{2} \mathrm{PO}_{4}, 1.0 \mathrm{~g} / \mathrm{liter}$; $\mathrm{pH}$ 7.0. Bacterial suspensions were adjusted to an absorbance at $600 \mathrm{~nm}\left(A_{600 \mathrm{~nm}}\right)=0.25$. Dilution plating was used to verify that inoculum at $A_{600 \mathrm{~nm}}=0.25$ consisted of $10^{7}$ to $10^{8} \mathrm{CFU} / \mathrm{ml}$.

Four rooted green cuttings of $V$. vinifera cv. Carignane with a minimum of six nodes were used per treatment in the greenhouse tests. The pin-pricking inoculation technique (12) was used to introduce both weakly virulent, protective strains of $X$. fastidiosa and highly pathogenic, challenge strains into xylem vessels of grapevine. Drops $(0.02 \mathrm{ml})$ of suspensions of weakly virulent strains were placed on opposite sides of both the second and third internodes from the stem base, which was pierced three to five times through each of the four drops with a dissecting needle. Bacterial suspensions were observed to be pulled into the pierced xylem vessels. Two weeks after introduction of a weakly virulent protective strain, $0.02-\mathrm{ml}$ drops of inoculum suspension of the highly virulent strain were inoculated into opposite sides of both the fourth and fifth internodes from the base of the stem. Inoculated plants were maintained for 6 months in a greenhouse at 18 to $23^{\circ} \mathrm{C}$ at night and 28 to $33^{\circ} \mathrm{C}$ in the daytime.

Plants were observed for symptoms of PD every 2 weeks for 6 months after inoculation. At each observation, culturing $X$. fastidiosa from petioles of symptomatic leaves confirmed visual diagnosis. After 6 months, severity ratings of the symptoms were made according to the following arbitrary scale: $0=$ no symptoms; 1 = any symptom of PD, such as marginal necrosis (MN) on the basal leaf; $2=\mathrm{MN}$ in one-third or less of the leaves; 3 = one-third to one-half of the leaves with MN; 4 = one-half to three-fourths of the leaves with $\mathrm{MN}$ and dead growing point; and $5=100 \%$ of the leaves with symptoms or a dead plant.

Biological control of $P D$ in vineyard tests. In the first trial in the MREC vineyard in Leesburg, $X$. fastidiosa strains Syc86-1 and PD-1, which had performed well in greenhouse tests (14), were evaluated for effectiveness against natural infection with PD in the vineyard. Ten 3- to 4year-old grapevines of a Florida bunch grape breeding line (Vitis sp.) were pruned back to the main trunk in early March 1992 and an American hybrid grape 'Himrod' (Vitis sp.) was grafted as the scion onto these plants. The Himrod scion stock was obtained from clean stock and maintained in vector-proof screenhouses or greenhouses prior to being grafted in the vineyard. In early April, when new shoot growth of Himrod was 30 to $45 \mathrm{~cm}$ long, the lower two internodes of shoots were inoculated at two spots with protective strains. Preparation of bacterial suspensions and techniques for introducing weakly virulent $X$. fastidiosa strains were as described for greenhouse tests. Three plants each were treated with PD-1 and Syc86-1 and four plants were left as nontreated controls. Infection of plants with PD occurred by natural infection through sharpshooter feeding, probably $H$. coagulata or $O$. nigricans.

The Himrod grapevines were rated for PD symptoms every 6 months for 2 years. At each observation, isolation of bacteria from petioles confirmed that symptoms were caused by a PD strain of $X$. fastidiosa. Pathogenic strains from natural infection were distinguished from the Syc86-1 strain by growth on PD3 and PW media (3) but could not be distinguished from the PD-1 strain. Every 6 months, severity ratings of symptoms were made according to the following arbitrary scale: $0=$ no symptoms; $1=$ any symptom of PD, such as $\mathrm{MN}$ on the basal leaf, interveinal chlorosis, or dieback; $2=\mathrm{MN}$ in one-third or less of the leaves; $3=$ one-third to onehalf of the leaves with $\mathrm{MN} ; 4=$ one-half to all of the leave with $\mathrm{MN}$ and dead growing point; and $5=$ dead plant.

Weakly virulent $X$. fastidiosa strains were evaluated in a random design. Mean disease severity ratings for each treatment were compared separately for each observation. Data were subjected to analysis of variance using the SAS statistical software (version 8.1; SAS Institute, Cary, NC).

In the second and third vineyard trials, six strains were evaluated, including strains that had provided good control of $\mathrm{PD}$ in the greenhouse tests described above or in tests previously reported (14), as well as other PD strains that had lost part or all of their virulence to grapevine during serial transfer. The strains tested were Syc86-1, EB92-1, PD91-2, PD-1, PD94-1, and PD95-6. Production of inoculum suspensions of $X$. fastidiosa strains was as described for the greenhouse experiment.

The second and third trials were conducted on $V$. vinifera cv. Flame Seedless on its own roots and on $V$. vinifera $\mathrm{cv}$. Cabernet Sauvignon grafted on 'Freedom' rootstock (Vitis sp.), respectively. Dormant cuttings of Flame Seedless and dormant bench grafts of Cabernet Sauvignon/ Freedom were obtained from clean stock and maintained in the screenhouse prior to being transplanted into the MREC, Leesburg vineyard in late March, 1997. On 4 to 10 June, when shoot growth was 45 to 75 $\mathrm{cm}$ in length, protective strains were inoculated into two spots in the second and third internodes of both cultivars by the pin pricking technique (12). Six plants of each cultivar were used per treatment. Infection of plants with virulent strains of PD occurred by natural feeding of indigenous sharpshooter vectors.

Flame Seedless plants were rated for PD symptoms every 6 months for 2 years. Flame Seedless did not grow very well on its own roots in Florida. Several plants died within a few months of transplanting After 2 years, the experiment was terminated because many of the vines were dying from root problems and foliar diseases, making it difficult to evaluate PD symptoms.

Cabernet Sauvignon plants were rated for PD symptoms every 6 months for 4 years. The experiment was terminated after 4 years because of the closing of the research farm at Leesburg. At each observation, culturing of $X$. fastidiosa from petioles was used to confirm visual symptoms. PD symptom severity ratings and statistical analyses were as described for the first vineyard experiment. 


\section{RESULTS}

Greenhouse tests. Rooted cuttings of Carignane grape that first were inoculated with $X$. fastidiosa strain EB92-1 and then inoculated 2 weeks later with the highly virulent strain PD92-8 did not develop PD symptoms during the 6-month test (Table 1). Cuttings first inoculated with strains Syc86-1 or EB92-2 and then challenged with the virulent strain developed mild severity rating of 1.0 compared with 5.0 in the pathogen control. There was only slight marginal reddening or necrosis in a leaf or two at the nodes nearest the inoculation site in the Syc86-1- and EB92-2-treated plants. EB92-2 produced mild symptoms in one plant that was not challenged with pathogen. Strain PD91-2 was ineffective for the control of PD in this greenhouse test. symptoms, demonstrated by a symptom

Himrod vineyard test. In this experiment, one of three vines inoculated with Syc86-1 developed symptoms, whereas all four nontreated vines developed PD symptoms (Fig. 1). All three vines treated with Syc86-1 survived the 2 years, but two of the nontreated vines died. Two of three vines treated with PD-1 developed symptoms and both plants died within the 2 years. Syc86-1-treated vines had a final average disease severity rating of 1.3 versus a 3.0 rating for control vines.

Flame Seedless and Cabernet Sauvignon vineyard tests. In the 2-year test on Flame Seedless, symptoms developed more quickly and were more severe in plants treated with strain PD91-2 than in nontreated plants (Fig. 2). PD-1 and PD941 (not shown) were similar to PD91-2. Only one of the Syc86-1-treated plants

Table 1. Biological control of Pierce's disease (PD) in 'Carignane' grapevine rooted cuttings in the greenhouse with avirulent or weakly virulent strains of Xylella fastidiosa

\begin{tabular}{lcc}
\hline Protection/challenge strain $^{\mathbf{a}}$ & Symptomatic/total plants & PD severity $^{\mathbf{b}}$ \\
\hline None/PD92-8 & $3 / 3$ & 5 \\
Syc86-1/None & $0 / 3$ & 0 \\
Syc86-1/PD92-8 & $2 / 3$ & 1.0 \\
PD91-2/None & $0 / 3$ & 0 \\
PD91-2/PD92-8 & $3 / 3$ & 4.7 \\
EB92-1/None & $0 / 3$ & 0 \\
EB92-1/PD92-8 & $0 / 3$ & 0 \\
EB92-2/None & $1 / 3$ & 1.0 \\
EB92-2/PD92-8 & $3 / 3$ & 1.0
\end{tabular}

a The second and third internodes from the base of the plant were inoculated with the protective strain and the challenge inoculation was into the fourth and fifth internodes.

b Severity ratings of PD symptoms were made on an arbitrary scale of 0 to 5 , where $0=$ no symptoms, $1=$ leaf marginal necrosis $(\mathrm{MN})$ in one to two basal leaves, $2=\mathrm{MN}$ in up to one-third of the leaves, 3 $=\mathrm{MN}$ in 30 to $50 \%$ of the leaves, $4=\mathrm{MN}$ in 50 to $75 \%$ of the leaves, and $5=\mathrm{MN}$ in all of the leaves or plant is dead. Average severity rating is given.

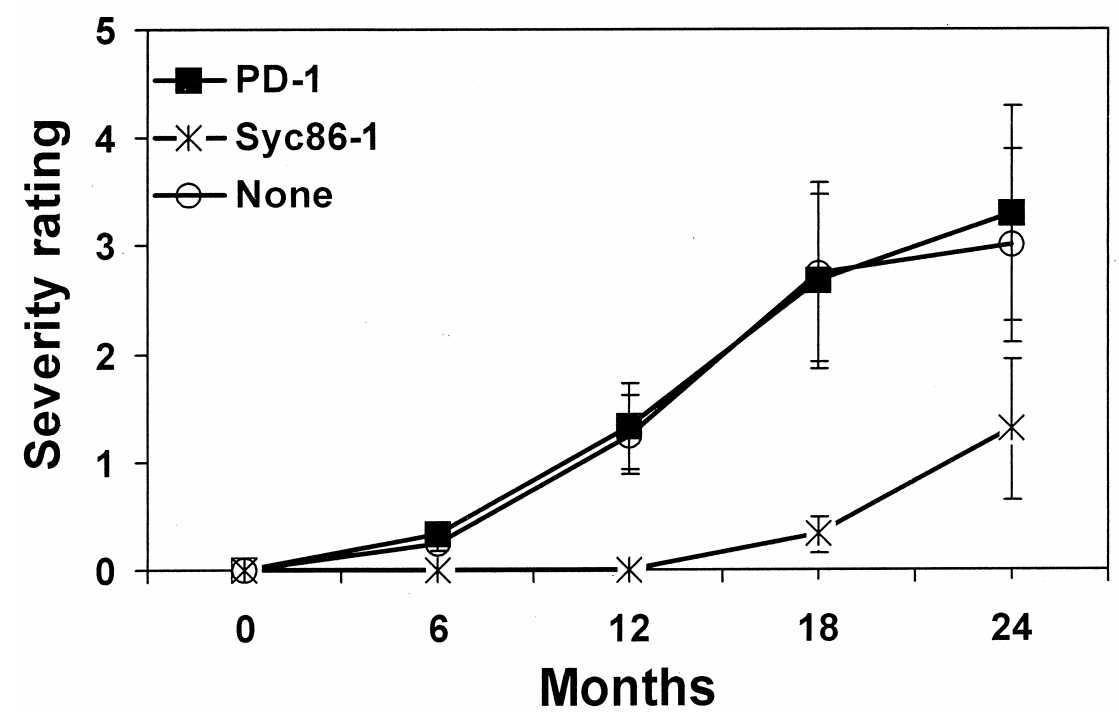

Fig. 1. Development of Pierce's disease (PD) symptoms in 'Himrod' grapevines grafted onto a Florida hybrid rootstock in the Mid-Florida Research and Education Center vineyard after inoculation of weakly virulent strains PD-1 and Syc86-1 of Xylella fastidiosa into the xylem vessels for biological control. Infection of the plants with PD occurred by natural feeding of indigenous sharpshooter vectors. Severity ratings of the symptoms were made according to the following arbitrary scale: $0=$ no symptoms; $1=$ any symptom of $\mathrm{PD}$, such as marginal necrosis $(\mathrm{MN})$ on the basal leaf; $2=\mathrm{MN}$ in onethird or less of the leaves; 3 = one-third to one-half of the leaves with MN; $4=$ one-half to all of the leaves with $\mathrm{MN}$ and dead growing point; and 5 = dead plant. Vertical bars represent standard error above and below the mean. survived transplanting; therefore, data was not available for this treatment. In the 18and 24-month ratings, strains EB92-1 and PD95-6 resulted in significantly lower severity of PD in Flame Seedless (Fig. 2).

All of the Cabernet Sauvignon plants grew very well during the first season. Only a few had PD symptoms in the fall, 6 months after transplanting; however, by the following September, over $80 \%$ of the nontreated vines had some symptoms of PD. Although PD91-2 appeared to delay symptom development for about 6 to 12 months, all of the nontreated vines as well as the vines treated with strains PD91-2 or PD94-1 were symptomatic by 30 months after transplanting (September 1999). Strains PD-1 and PD95-6 did not result in lower PD incidence when compared with the nontreated. Only $50 \%$ of the vines treated with strain EB92-1 developed PD symptoms before the termination of the experiment 4 years after planting.

In addition to differences in incidence of PD among treatments, there were differences in symptom severity. The average severity rating for vines treated with strain EB92-1 was significantly lower than any other treatment throughout the experiment and was less than 2.0 after 4 years (Fig. 3). Only one vine treated with this strain developed severe symptoms during the test; the rest had either no symptoms or minor leaf necrosis in September to October and still produced fruit during the fourth year of this trial. Symptoms developed later in plants treated with strain PD91-2, resulting in significantly lower disease severity after 24 months; however, by 30 months after transplanting, these vines were similar to the nontreated controls. None of the other strains resulted in lower severity of PD symptoms.

Twelve months after transplanting, Cabernet Sauvignon vines that were either nontreated or treated with Syc86-1 or PD94-1 began dying (Fig. 4). All vines in the control and PD94-1 treatments were dead by the end of the 4-year trial; one vine treated with Syc86-1 survived. All vines treated with PD-1 or PD95-6 also died (data not shown). Treatment with PD91-2 provided some control of PD, with the first vine death occurring 30 months after transplanting (Fig. 4). At the end of the experiment, $60 \%$ of the vines treated with PD91-2 had died. In the vines treated with strain EB92-1, only a single vine died, and this occurred during the last year of the trial. All other vines in this treatment were still growing vigorously and producing fruit.

\section{DISCUSSION}

In an earlier greenhouse study, weakly virulent strains of $X$. fastidiosa, PD-1 and Syc86-1, inoculated into the lower internodes of Carignane grapevines provided protection against inoculation 2 weeks later with a highly virulent strain (14). 
These plants developed mild or no symptoms. In the current study, these two strains were evaluated in a 2-year vineyard test on Himrod. PD-1 was ineffective; however, Syc86-1 continued to be promising as a biological control treatment for PD and demonstrated that it was possible to obtain field control of PD with benign strains of $X$. fastidiosa. Greenhouse tests have identified several other strains of $X$. fastidiosa that were avirulent or weakly virulent to grapevine and which protected against virulent strains in Carignane grapevine.

Under conditions favorable for PD development, strain EB92-1 provided excellent control of PD in a new planting of $V$. vinifera cv. Cabernet Sauvignon for 4 years, when compared with the nontreated vines. Only one vine developed severe symptoms and died. Other vines continued to grow and produce fruit when all nontreated vines were dead. Strain PD91-2 was effective in preventing symptoms of PD for 12 to 18 months; however, by the end of the test, disease severity was similar to the control. None of the other strains were effective in controlling PD in Cabernet Sauvignon in the vineyard. Even strain Syc86-1, which had provided some control in Himrod budded onto a Florida bunch grape, failed to control PD in this test. This test also was run on Flame Seedless, where EB92-1 was an effective treatment. However, the Flame Seedless plants on their own roots did not grow well in Florida.

Many strains that provided control in 6month greenhouse tests failed to control PD in the vineyard. Conditions are much more controlled in the greenhouse and the virulent pathogen is inoculated into the plant at a single time after introduction of the biological control strain into the plant; whereas, in the field, vectors may transmit the bacterium to the host multiple times daily. In vineyards in central Florida, the vine must be protected against infection at any time. In the earlier greenhouse studies, avirulent strains of $X$. fastidiosa that were localized after inoculation and that did not multiply and systemically colonize the plant failed to provide protection $(12,14)$. Only strains that were able to multiply and systemically colonize without producing significant symptoms were able to protect against virulent strains. Perhaps this ability to continue to slowly colonize a grapevine, even from one season to the next, is the determining factor in providing biological control of PD in the vineyard. Alternatively, there could be some phenotypic differences between strains, other than colonization or host cultivar specificity, that are required for successful biological control of PD in the vineyard. The most effective biological control strain was EB92-1. It is closely related to PD strains from grapevine but is genetically different. Its primary host is elderberry (19). The other strain that performed well in earlier tests, Syc86-1, also differs from grapevine strains in primary host and DNA fingerprint (14). However, one grapevine strain that had lost virulence did lower the development of PD symptoms for 12 to 18 months.

Why Syc86-1 failed to provide any control of PD in the Cabernet Sauvignon and Flame Seedless vineyard trials after per- forming well in earlier greenhouse tests and the short field experiment on Himrod remains unexplained. Perhaps there are specific interactions between biological control strains and grape cultivars, or biological control may be most effective on cultivars that have some genetic tolerance to PD. In addition, we do not know if Syc86-1 would have continued to provide

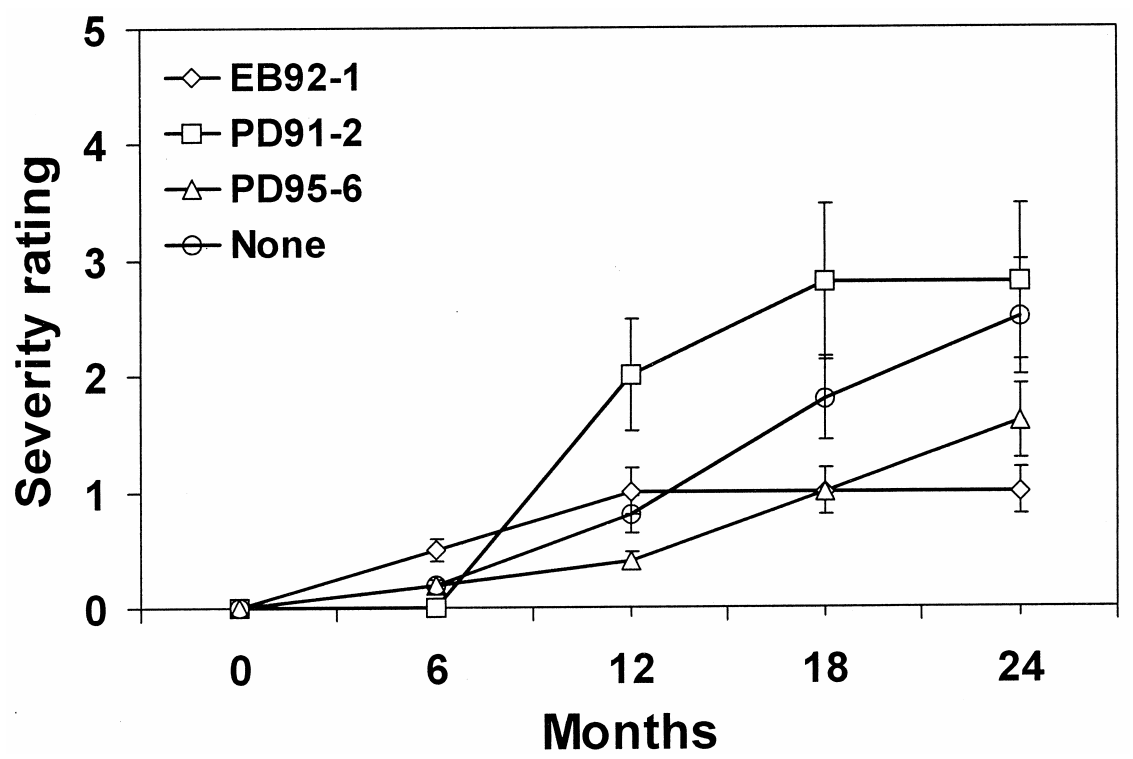

Fig. 2. Development of Pierce's disease (PD) symptoms in 'Flame Seedless' grapevines in the MidFlorida Research and Education Center vineyard after inoculation of weakly virulent strains of Xylella fastidiosa into the xylem vessels for biological control. Infection of the plants with PD occurred by natural feeding of indigenous sharpshooter vectors. Severity ratings of the symptoms were made according to the following arbitrary scale: $0=$ no symptoms; $1=$ any symptom of $\mathrm{PD}$, such as marginal necrosis $(\mathrm{MN})$ on the basal leaf; $2=\mathrm{MN}$ in one-third or less of the leaves; $3=$ one-third to one-half of the leaves with MN; $4=$ one-half to all of the leaves with $\mathrm{MN}$ and dead growing point; and $5=$ dead plant. Vertical bars represent standard error above and below the mean.

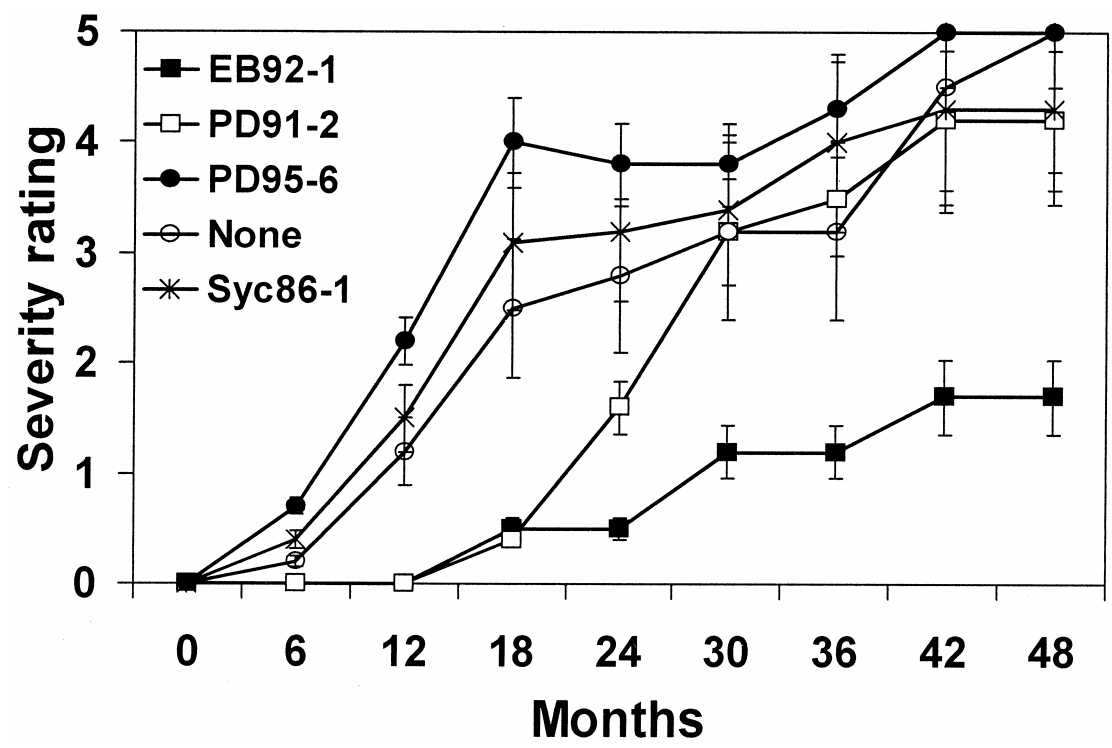

Fig. 3. Development of Pierce's disease (PD) symptoms in 'Cabernet Sauvignon/Freedom' grapevines in the Mid-Florida Research and Education Center vineyard after inoculation of weakly virulent strains of Xylella fastidiosa into the xylem vessels for biological control. Infection of the plants with PD occurred by natural feeding of indigenous sharpshooter vectors. Severity ratings of the symptoms were made according to the following arbitrary scale: $0=$ no symptoms; $1=$ any symptom of PD, such as marginal necrosis $(\mathrm{MN})$ on the basal leaf; $2=\mathrm{MN}$ in one-third or less of the leaves; $3=$ one-third to one-half of the leaves with $\mathrm{MN} ; 4$ = one-half to all of the leaves with $\mathrm{MN}$ and dead growing point; and $5=$ dead plant. Vertical bars represent standard error above and below the mean. 


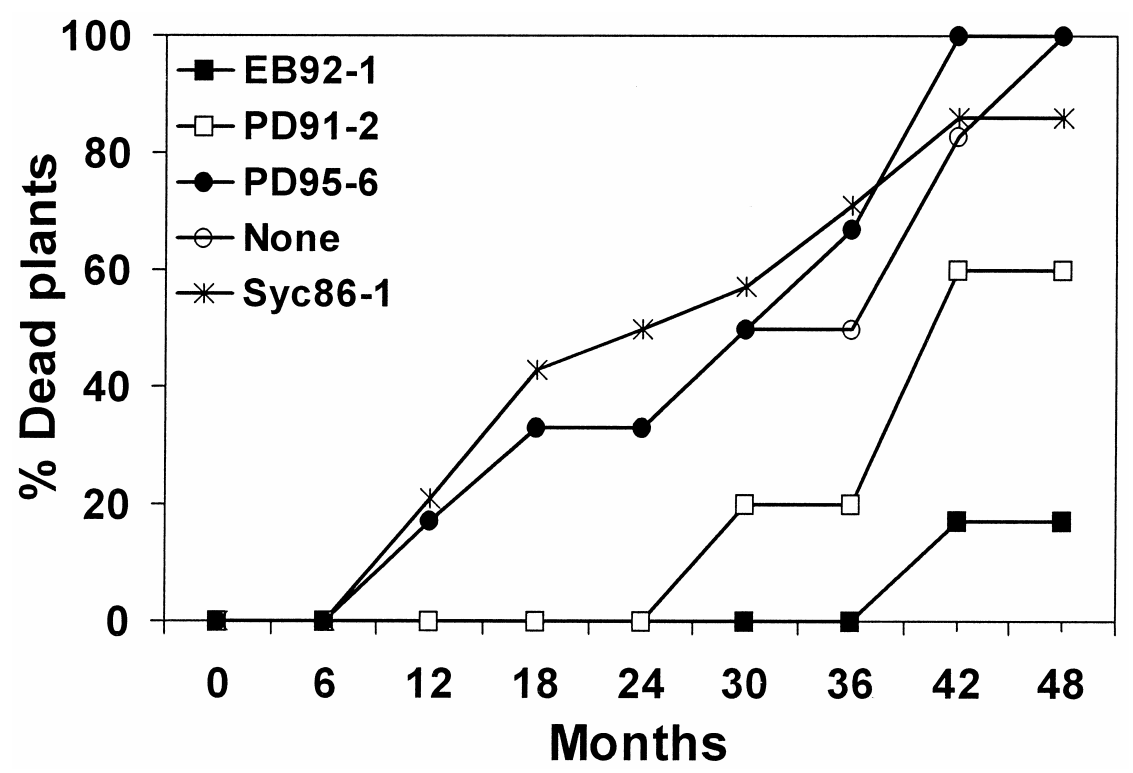

Fig. 4. Mortality of 'Cabernet Sauvignon/Freedom' grapevines over time due to Pierce's disease (PD) after inoculation of weakly virulent strains of Xylella fastidiosa into the xylem vessels for biological control. Infection of the plants with PD occurred by natural feeding of indigenous sharpshooter vectors.

control of PD in Himrod over a longer time. Effectiveness of EB92-1 on various grape cultivars currently is being evaluated in research and commercial vineyards in Florida. Also, PD strains of $X$. fastidiosa can lose virulence to grapevine during weekly serial transfer (12). Therefore, pathogenic strains are stored by lyophilization or in glycerol at $-70^{\circ} \mathrm{C}$ and utilized as soon as possible after recovery from storage. Virulence and rate of systemic colonization were correlated (12). Biological control of PD by benign strains of $X$. fastidiosa also was associated with the ability to colonize grapevine (14). Perhaps the Syc86-1 strain lost this capability during storage and serial transfer prior to the last vineyard trials. Proper storage and maintenance of the strains (i.e., EB92-1) would appear to be most important for consistent biological control activity.

In conclusion, $X$. fastidiosa strain EB921 provided excellent control of PD in $V$. vinifera cv. Cabernet Sauvignon for 4 years in the vineyard in central Florida. Strain EB92-1 was inoculated into the vines only once at the beginning of the 4year trial and was still controlling the disease at the end, whereas all unprotected vines were dead. With the closing of the vineyard in Leesburg, two of the vines treated with strain EB92-1 were transferred to a large pot until the vineyard was developed at the MREC in Apopka. These two vines were moved into the vineyard in the spring of 2002. These vines produced fruit in their second season at the new location and still appeared to be healthy in 2005 , after 4 years in a new vineyard in Apopka, FL and 8 years after treatment.
Inoculation with benign strains of $X$. fastidiosa, especially strain EB92-1, appears to have potential for the biological control of $\mathrm{PD}$ in the commercial vineyard in Florida and, perhaps, wherever PD occurs. To obtain further confirmation of this research with different cultivars and larger numbers, experiments currently are being conducted in commercial vineyards in Florida, as well as in the University of Florida vineyard.

\section{LITERATURE CITED}

1. Adlerz, W. C. 1980. Ecological observations on two leafhoppers that transmit the Pierce's disease bacterium. Proc. Fla. State Hortic. Soc. 93:115-120.

2. Adlerz, W. C., and Hopkins, D. L. 1979. Natural infectivity of two sharpshooter vectors of Pierce's disease of grape in Florida. J. Econ. Entomol. 72:916-919.

3. Davis, M. J., French, W. J., and Schaad, N. W. 1981. Axenic culture of the bacteria associated with phony disease of peach and plum leaf scald. Curr. Microbiol. 6:309-314.

4. Davis, M. J., Purcell, A. H., and Thomson, S. V. 1978. Pierce's disease of grapevines: isolation of the causal bacterium. Science 199:7577.

5. Davis, M. J., Purcell, A. H., and Thomson, S. V. 1980. Isolation medium for Pierce's disease bacterium. Phytopathology 70:425-429.

6. Davis, M. J., Whitcomb, R. F., and Gillaspie, A. G. Jr. 1980. Fastidious bacteria of plant vascular tissue and invertebrates (including socalled rickettsia-like bacteria). Pages 21722188 in: The Prokaryotes: A Handbook on Habitats, Isolation, and Identification of Bacteria. M. P. Starr, H. O. Stolp, H. G. Truper, A. Balows, and H. G. Schlegel, eds. SpringerVerlag, New York/Heidelberg/Berlin.

7. De Lima, J. E. O., Miranda, V. S., Hartung, J. S., Brlansky, R. H., Coutinho, A., Roberto, S. R., and Carlos, E. F. 1998. Coffee leaf scorch bacterium: Axenic culture, pathogenicity, and comparison with Xylella fastidiosa of citrus. Plant Dis. 82:94-97.
8. Freitag, J. H. 1951. Host range of Pierce's disease virus of grapes as determined by insect transmission. Phytopathology 41:920-934.

9. Goheen, A. C., Nyland, G., and Lowe, S. K. 1973. Association of a rickettsia-like organism with Pierce's disease of grapevines and alfalfa dwarf and heat therapy of the disease in grapevines. Phytopathology 63:341-345.

10. Hearon, S. S., Sherald, J. L., and Kostka, S. J. 1980. Association of xylem-limited bacteria with elm, sycamore, and oak leaf scorch. Can. J. Bot. 58:1986-1993.

11. Hopkins, D. L. 1984. Variability of virulence in grapevine among isolates of Pierce's disease bacterium. Phytopathology 74:1395-1398.

12. Hopkins, D. L. 1985. Physiological and pathological characteristics of virulent and avirulent strains of the bacterium that causes Pierce's disease of grapevine. Phytopathology 75:713717.

13. Hopkins, D. L. 1989. Xylella fastidiosa: Xylem-limited bacterial pathogen of plants. Annu. Rev. Phytopathol. 27:271-290.

14. Hopkins, D. L. 1992. Induced resistance to Pierce's disease of grapevine by weakly virulent strains of Xylella fastidiosa. Pages 951956 in: Proc. 8th Int. Conf. Plant Pathol. Bacteria. Versailles, France.

15. Hopkins, D. L., and Adlerz, W. C. 1988. Natural hosts of Xylella fastidiosa in Florida. Plant Dis. 72:429-431.

16. Hopkins, D. L., and Mollenhauer, H. H. 1973. Rickettsia-like bacterium associated with Pierce's disease of grapes. Science 179:298-300.

17. Hopkins, D. L., Mollenhauer, H. H., and Mortensen, J. A. 1974. Tolerance to Pierce's disease and the associated rickettsia-like bacterium in muscadine grape. J. Am. Soc. Hortic. Sci. 99:436-439.

18. Hopkins, D. L., and Purcell, A. H. 2002. Xylella fastidiosa: Cause of Pierce's disease of grapevine and other emergent diseases. Plant Dis. 86:1056-1066.

19. Hopkins, D. L., and Wichman, R. W. 2001. Pathogenic and molecular relationships among strains of Xylella fastidiosa from grapevine and American elder. Pages 161-164 in: Proc. 10th Int. Conf. Plant Pathol. Bacteria. Charlottetown, Prince Edward Island, Canada.

20. Purcell, A. H. 1974. The spatial distribution of Pierce's disease in the Napa Valley. Am. J. Enol. Vitic. 25:162-167.

21. Purcell, A. H. 1990. Homopteran transmission of xylem-inhabiting bacteria. Pages 243-266 in: Advances in Disease Vector Research, vol. 5. K. F. Harris, ed. Springer-Verlag, New York.

22. Raju, B. C., and Goheen, A. C. 1981. Relative sensitivity of selected grapevine cultivars to Pierce's disease bacterial inoculations. Am. J. Enol. Vitic. 32:155-158.

23. Schaad, N. W., Postnikova, E., Lacy, G., Fatmi, M., and Chang, C. J. 2004. Xylella fastidiosa subspecies: X. fastidiosa subsp. piercei, subsp. nov., $X$. fastidiosa subsp. multiplex subsp. nov., and $X$. fastidiosa subsp. pauca subsp. nov. Syst. Appl. Microbiol. 27:290-300.

24. Sticher, L., Mauch-Mani, B., and Metraux, J. P. 1997. Systemic acquired resistance. Annu. Rev. Phytopathol. 35:235-270.

25. Stoner, W. N. 1953. Leafhopper transmission of a degeneration of grape in Florida and its relation to Pierce's disease. Phytopathology 43:611-615.

26. Wells, J. M., Raju, B. C., Hung, H. Y., Weisburg, W. G., Mandelco-Paul, L., and Brenner, D. J. 1987. Xylella fastidiosa gen. nov. sp. nov: gram-negative, xylem-limited, fastidious plant bacteria related to Xanthomonas spp. Int. J. Syst. Bacteriol. 37:136-143. 